\title{
ХАРАКТЕРИСТИКИ ТЕЧЕНИЯ LАDА-ДИАБЕТА У ЛИЦ МОЛОДОГО ВОЗРАСТА
}

\author{
'Галенок Р.Б., ${ }^{2}$ Овсянникова А.К., ${ }^{2}$ Рымар О.Д. \\ 'ФГБОУ ВО «Новосибирский государственный медицинский университет» Министерства здравоохранения \\ Российской Федерации, Новосибирск \\ ${ }^{2}$ Научно-Исследовательский Институт терапии и профилактической медицины-филиал Федерального \\ государственного бюджетного научного учреждения «Федеральный исследовательский центр Институт \\ Цитологии и генетики Сибирского отделения Российской академии наук»
}

Проведение дифференциальной диагностики типа сахарного диабета (СД) при классическом дебюте заболевания обычно не вызывает затруднений. Однако в последнее время все чаще встречаются формы СД, которые сразу сложно отнести к диабету 1 (СД 1) или 2 типа (СД 2). Одним из вариантов течения аутоиммунного СД является латентный аутоиммунный диабет взрослых — «latent autoimmune diabetes in adults» (LADA). Данная форма СД занимает промежуточное положение между СД 1 и СД 2 и в последней классификации («Алгоритмы специализированной медицинской помощи больным сахарным диабетом» под редакцией И.И. Дедова 2020 г.) не выделяется в отдельную номенклатурную единицу. Наличие в дебюте заболевания клинической картины СД 2 затрудняет диагностику и соответственно, адекватное ведение пациентов с LADA. В связи с этим изучение течения LADA, в том числе, эффективность антигипергликемической терапии имеет большое практическое значение.

ЦЕЛЬ: изУчить особенности течения LADA-диабета.

МАТЕРИАЛЫ И МЕТОДЫ: было обследовано 238 человек с началом сахарного диабета до 45 лет в НИИТПМ-филиал ИЦиГ СО РАН. Проведен полный клинический осмотр, биохимический и гормональный анализы (С-пептид, тиреотропный гормон) крови, определение гликированного гемоглобина, антитела к b-клеткам, антитела к GAD (Glutamate decarboxylase), антитела к инсулину. Среди всего количества пациентов у 12 (5,0\%) диагностирован LADA-диабет.

PEЗУЛЬТАТЫ: среди 12 пациентов определено, что преобладают пациенты женского пола (8 пациентов - 66,6\%) по сравнению с мужским полом (4 пациента-33,4\%) ( $p=0,001)$, медиана возраста на момент диагностики заболевания составляет 35 [32; 44] лет, медиана продолжительности течения заболевания 10 [1;12] лет. Выявлено, что преобладают такие сопутствующие заболевания как: аутоиммунный тиреоидит (4 пациента-33,3\%), бронхиальная астма (3 пациента-25,0\%). У 2 пациентов (16,6\%) из осложнений в анамнезе присутствовала гипогликемическая кома, и полинейропатия, также у всех пациентов в анамнезе была потеря веса до 10 кг.

Медиана гликированного гемоглобина составляла 7,5 [7,1;9,2] \%; антитела к b-клеткам были положительными у 3 пациентов (25,0\%), антитела к GAD - у 6 пациентов (50,0\%), к инсулину — у 2 (16,6\%); медиана тиреотропного гормона - $1.6[1,1 ; 4,1]$ мкME/мл; С-пептид был ниже референсных значений у 3 пациентов (25,0\%). 9 пациентов (75,0\%) принимают антигипергликемические препараты (из них 75,0\% - инсулин, $25,0 \%$ - пероральные сахароснижающие препараты), однако 3 пациента $(25,0 \%)$ обходятся без лекарственной терапии.

\section{ВЫВоды:}

1. LADA-диабет диагностируется в $5 \%$ случаев у лиц молодого возраста, значительно чаще среди лиц женского пола.

2. Среди исследуемых видов антител превалируют антитела к GAD, поэтому при скрининге на LADAдиабет в первую очередь рекомендовано изучать эти антитела.

3. У трети пациентов с LADA-диабетом диагностируется аутоиммунный тиреоидит, поэтому необходимо проводить скрининг на данную патологию у лиц с этим типом сахарного диабета.

КЛЮЧЕВЫЕ СЛОВА:LADA-диабет; молодые пачиенты; c-nептид 